\title{
Design and Synthesis of a Fluorescent Probe Based on Copper Complex for Selective Detection of Hydrogen Sulfide
}

\author{
Guanglan Mao $\mathbb{D},{ }^{1}$ Chenxi Liu $\mathbb{D},{ }^{2}$ Nan Yang $\mathbb{D},{ }^{2}$ Linlin Yang $\mathbb{D},{ }^{2}$ and Guangjie He $\mathbb{C}^{2}$ \\ ${ }^{1}$ Department of Traditional Chinese Medicine, The Third Affiliated Hospital of Xinxiang Medical College, East Section of \\ Hualan Avenue, Xinxiang, 453000 Henan Province, China \\ ${ }^{2}$ Xinxiang Key Laboratory of Forensic Science Evidence, School of Forensic Medicine, Xinxiang Medical University, Jinsui Road \\ No. 601, Xinxiang, 453003 Henan Province, China
}

Correspondence should be addressed to Guangjie He; guangjiehe@163.com

Received 20 September 2020; Revised 29 January 2021; Accepted 2 February 2021; Published 16 February 2021

Academic Editor: Roberto Paolesse

Copyright (C) 2021 Guanglan Mao et al. This is an open access article distributed under the Creative Commons Attribution License, which permits unrestricted use, distribution, and reproduction in any medium, provided the original work is properly cited.

\begin{abstract}
A novel fluorescence probe NA-LCX was rationally designed and synthesized for the sequential recognition of $\mathrm{Cu}^{2+}$ and $\mathrm{H}_{2} \mathrm{~S}$ by the combination of hydroxyl-naphthalene and diformylphenol groups. The response properties of NA-LCX for $\mathrm{Cu}^{2+}$ ions and $\mathrm{H}_{2} \mathrm{~S}$ with "on-off-on" manner were investigated by fluorescence emission spectra. A highly selective and sensitive response of complex NALCX-Cu ${ }^{2+}$ for $\mathrm{H}_{2} \mathrm{~S}$ over other competing amino acids was observed with a limit of detection at $2.79 \mu \mathrm{M}$. The stoichiometry of NALCX toward $\mathrm{Cu}^{2+}$ ions was determined to be $1: 1$ by the UV-Vis absorption spectrum, and the coordination configuration was calculated by density functional theory (DFT) calculations. Moreover, probe NA-LCX was applied successfully for the recognition of $\mathrm{Cu}^{2+}$ ions and $\mathrm{H}_{2} \mathrm{~S}$ in living cells.
\end{abstract}

\section{Introduction}

Hydrogen sulfide $\left(\mathrm{H}_{2} \mathrm{~S}\right)$, the simplest biomercapto compound, is not only a rotten egg smelling gas pollutant but also the third gasotransmitter and cellular signaling molecule after $\mathrm{CO}$ and $\mathrm{NO}[1,2]$. The endogenous $\mathrm{H}_{2} \mathrm{~S}$ could regulate vascular smooth muscle tension and cardiac contractile function, anti-inflammatory and antioxidative stress, neurotransmitter transmission, and insulin signaling inhibition, which plays an important role in the physiological and pathological processes of the cardiovascular, nervous, immune, and digestive systems [3-7]. The concentrations of $\mathrm{H}_{2} \mathrm{~S}$ in the normal metabolism often maintain dynamic equilibrium, while abnormal changes of the $\mathrm{H}_{2} \mathrm{~S}$ level could induce serious health problems, such as heart diseases $[8,9]$, chronic obstructive pulmonary diseases $[10,11]$, cirrhosis $[12,13]$, and Alzheimer $[14,15]$. Hence, it is crucial to exploit a highly sensitive and selective method for the detection of hydrogen sulfide in living systems.

Many conventional methods for $\mathrm{H}_{2} \mathrm{~S}$ detection have been developed, including colorimetric method [16, 17], electro- chemical analysis $[18,19]$, liquid chromatography mass spectrometry [20, 21], and fluorescence analysis [22-24]. Among them, fluorescence analysis is more desirable due to its simple operation, high sensitivity, wide dynamic range, high fluorescence quantum yield, good biocompatibility, noninvasiveness, and ability of in situ real-time detection in living systems [25]. In recent years, many fluorescent probes for $\mathrm{H}_{2} \mathrm{~S}$ detection have been reported on account of different types of strategies such as reduction reactions [26, 27], nucleophilic addition reactions [28, 29], dinitrophenyl ether/sulfonyl ester cleavage [30,31], and metal sulfide precipitation reaction [32-40]. However, there are some limitations to those reaction methods as well as the products obtained via those reactions. For example, those reactions are insensitive, complex, and time-consuming; moreover, fluorescent probes prepared via those reactions are sometimes not biocompatible and sometimes unstable in the presence of biological thiols (glutathione, cysteine, etc.) [31]. The strategy by using a metal displacement approach is in high demand for its fast response and high sensitivity and selectivity. Sulfide is known to react with copper ion to form very stable CuS with a very 


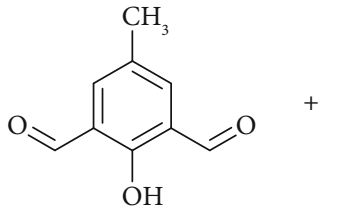<smiles>NNC(=O)c1cc2ccccc2cc1O</smiles><smiles>Cc1cc(/C=N/NC(=O)c2cc3ccccc3cc2O)c(O)c(/C=N/NC(=O)c2cc3ccccc3cc2O)c1</smiles>

NA-LCX

Scheme 1: Synthesis route of ligand NA-LCX.

low solubility product constant $K_{\mathrm{sp}}=6.3 \times 10^{-36}$ (for cyanide, $K_{\mathrm{sp}}=3.2 \times 10^{-20}$ ). Thus, the utilization of the higher affinity of $\mathrm{Cu}^{2+}$ towards sulfide for designing a specific $\mathrm{Cu}^{2+}$ sensor to sequentially identify $\mathrm{H}_{2} \mathrm{~S}$ has received considerable attention because it can effectively eliminate the interference of other analytes in the system.

Naphthalene derivatives with an electron donor- $\pi$-acceptor $(\mathrm{D}-\pi-\mathrm{A})$ structure have been widely used due to good optical properties, such as high fluorescence quantum yield, good biocompatibility, and light stability. Herein, we synthesized a new fluorescent probe NA-LCX based on hydroxylnaphthalene and diformylphenol which have excellent coordination ability to metal ions. The probe showed an obvious "on-off” fluorescence quenching response toward $\mathrm{Cu}^{2+}$, and the NA-LCX-Cu ${ }^{2+}$ complex showed an "off-on" fluorescence enhancement response toward $\mathrm{H}_{2} \mathrm{~S}$ in a DMSO/HEPES $(3: 2$ $v / v, \mathrm{pH}=7.4)$. The photophysical capabilities of probe NALCX for $\mathrm{Cu}^{2+}$ and NA-LCX-Cu ${ }^{2+}$ for $\mathrm{H}_{2} \mathrm{~S}$ were studied in details from fluorescence spectroscopy, absorption spectroscopy, and fluorescence images in vivo.

\section{Experimental Section}

2.1. Reagents and Materials. 2,6-Diformyl-4-methylphenol was purchased from Shanghai TCI Chemical Industry Development Co. Ltd. 3-Hydroxy-2-naphthoyl hydrazide was purchased from Sinopharm Chemical Reagent Co. Ltd. All the other chemicals and reagents were commercially available and were analytical grade. All solvents were purified by standard procedures. Aqueous solutions $\left(2.0 \times 10^{-2} \mathrm{M}\right)$ of perchlorates of various metal ions $\left(\mathrm{Al}^{3+}, \mathrm{K}^{+}, \mathrm{Na}^{+}, \mathrm{Mg}^{2+}, \mathrm{Ca}^{2+}\right.$, $\mathrm{Cr}^{3+}, \mathrm{Mn}^{2+}, \mathrm{Fe}^{2+}, \mathrm{Fe}^{3+}, \mathrm{Co}^{2+}, \mathrm{Ni}^{2+}, \mathrm{Zn}^{2+}, \mathrm{Cd}^{2+}, \mathrm{Hg}^{2+}, \mathrm{Ag}^{+}$, $\mathrm{Pb}^{2+}$, and $\mathrm{Cu}^{2+}$ ) and various amino acids (Asn, Glu, Cys, Phe, Pro, Gln, Arg, Trp, Asp, Tyr, Ile, Thr, His, Gly, Met, Leu, Ala, Val, Ser, Lys, Cys, GSH, Hcy, and NAC) were prepared before use.

2.2. Apparatus and Instruments. The following are the apparatus and instruments used in the study: UV-Vis spectrophotometer (UV-2600, Shimadzu Corporation), fluorescence spectrophotometer (FS5, Edinburgh, UK), nuclear magnetic resonance spectrometer (NMR) (Ascend ${ }^{\mathrm{TM}}$ 400, Bruker Co., USA), precision $\mathrm{pH}$ meter (PHS-3E, Zhengzhou Tailai Instruments Co., Ltd.), and inverted fluorescence microscope (Leica DMI8, Leica Microsystems, Germany).
2.3. Synthesis of the Probe NA-LCX. 3-Hydroxy-2-naphthohydrazide $(0.40 \mathrm{~g}, 2.0 \mathrm{mmol})$ and 2,6-diformyl-4-methylphenol $(0.164 \mathrm{~g}, 1.0 \mathrm{mmol})$ were dissolved in $30 \mathrm{~mL}$ of ethanol, respectively. Then, the solution was mixed dropwise and refluxed for 6 hours. The obtained mixture was filtered, washed, and vacuum dried to afford ligand NA-LCX (Scheme 1). ${ }^{1} \mathrm{H}$ NMR (400 MHz, d $\mathrm{d}^{6}$-DMSO), $\delta 8.76$ (s, 2H), $8.48(\mathrm{~s}, 2 \mathrm{H}), 7.94(\mathrm{~d}, J=8.2 \mathrm{~Hz}, 2 \mathrm{H}), 7.78(\mathrm{~d}, J=8.2 \mathrm{~Hz}, 2 \mathrm{H})$, $7.61(\mathrm{~s}, 2 \mathrm{H}), 7.53(\mathrm{t}, J=7.6 \mathrm{~Hz}, 2 \mathrm{H}), 7.37 \quad(\mathrm{dd}, J=14.7$, $7.1 \mathrm{~Hz}, 4 \mathrm{H}), 2.36$ (s, 3H). ${ }^{13} \mathrm{C}$ NMR (101 MHz, d $\mathrm{d}^{6}$-DMSO), $\delta 164.23,155.37,154.54,147.20,136.36,130.95,130.72$, $129.15,128.76,127.24,126.35,124.31,120.70,120.33$, and 111.02, 20.41. MS: calculated $\left[(\mathrm{M}+\mathrm{Na})^{+}\right]$555.1644; found 555.1638 .

2.4. Synthesis of Complex $N A-L C X-C u^{2+}$. In a $50 \mathrm{~mL}$ round bottom flask, ligand NA-LCX $(0.053 \mathrm{~g}, 0.1 \mathrm{mmol})$ and $\mathrm{Cu}\left(\mathrm{ClO}_{4}\right)_{2} \cdot 6 \mathrm{H}_{2} \mathrm{O}(0.037 \mathrm{~g}, 0.1 \mathrm{mmol})$ were mixed in $15 \mathrm{~mL}$ methanol. After being stirred for 30 minutes, the obtained precipitate was filtered, washed, and dried to afford the NA-LCX-Cu ${ }^{2+}$ complex.

2.5. General Method for Cell Imaging. Human liver cancer HepG-2 cells were cultured in a 12 -well plate, and when the cell saturation exceeded $80 \%$, ligand NA-LCX and probe NA-LCX-Cu ${ }^{2+}$ solution were added. The mixture was then incubated for 3 hours in a $\mathrm{CO}_{2}$ incubator and washed three times with precooled PBS, followed by the addition of $1 \mathrm{~mL}$ PBS. The resulting mixture was observed under a Leica DMI8 inverted fluorescence microscope.

\section{Results and Discussion}

3.1. UV-Vis Spectrum Recognition of Probe NA-LCX toward $\mathrm{Cu}^{2+}$. UV-Vis absorption spectra of ligand NA-LCX $(20 \mu \mathrm{M})$ in the presence of $\mathrm{Cu}^{2+}$ ions in DMSO:HEPES $(3: 2, v / v$, $\mathrm{pH}=7.4)$ at various concentrations were performed in Figure 1. Upon the addition of $\mathrm{Cu}^{2+}$ ions, the UV-Vis absorption intensities of ligand NA-LCX at $312 \mathrm{~nm}$ and $366 \mathrm{~nm}$ decreased gradually, while the intensities at $346 \mathrm{~nm}$ and $438 \mathrm{~nm}$ increased with a change in color from yellowish to orange. A plateau was reached for the $438 \mathrm{~nm}$ wavelength upon the addition of about 1.5 equivalents of $\mathrm{Cu}^{2+}$ ions. To further determine the molar ratio of probe NA-LCX to $\mathrm{Cu}^{2+}$ ions, Job's plot fitting was performed and the molar ratio of 


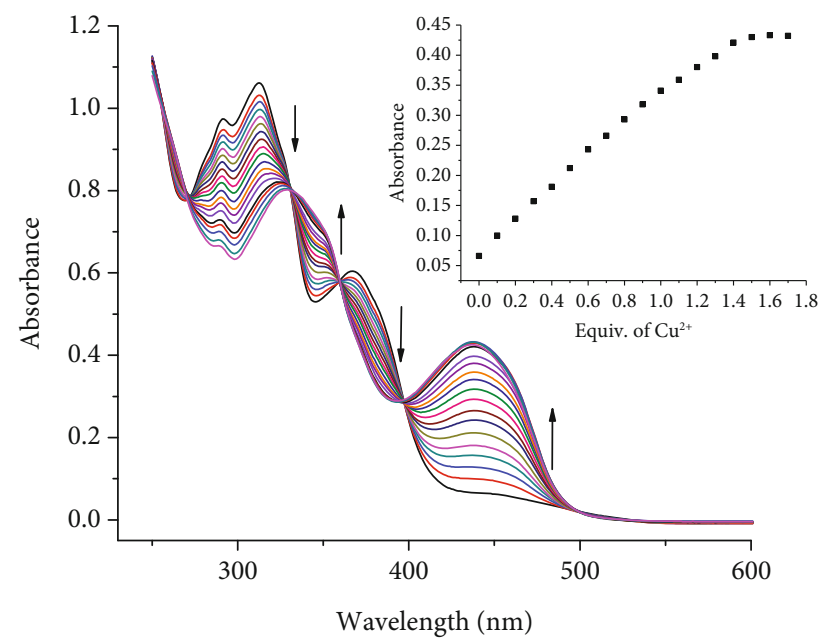

Figure 1: UV-Vis spectrum of ligand NA-LCX $(20 \mu \mathrm{M})$ with the addition of $\mathrm{Cu}^{2+}$ ions in DMSO $\operatorname{HEPES}(3: 2, v / v)$. Inset figure: the absorption intensity of ligand NA-LCX at $438 \mathrm{~nm}$ with the addition of $\mathrm{Cu}^{2+}$ ions.

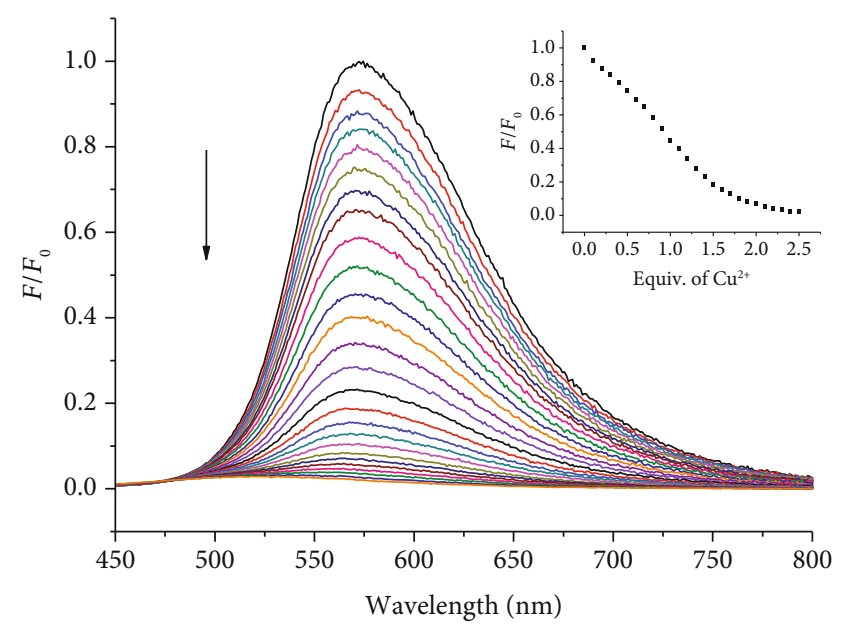

FIGURE 2: Fluorescence spectra of $\mathrm{Cu}^{2+}$ ions with probe NA-LCX $(20 \mu \mathrm{M})$ in DMSO : HEPES $(3: 2, v / v)$ at an excitation of $312 \mathrm{~nm}$. Inset figure: $F / F_{0}$ for probe NA-LCX at $575 \mathrm{~nm}$ upon the addition of different equivalents of $\mathrm{Cu}^{2+}$ ions.

ligand NA-LCX to $\mathrm{Cu}^{2+}$ was determined as $1: 1$ based on the continuous changes in absorbance at $438 \mathrm{~nm}$ (Figure S4).

3.2. Fluorescence Spectroscopy Recognition of Probe NA-LCX toward $\mathrm{Cu}^{2+}$. The sensitivity of probe NA-LCX for $\mathrm{Cu}^{2+}$ was investigated by fluorescence titration. Probe NA-LCX showed a strong fluorescence emission peak at $575 \mathrm{~nm}$ upon excitation at $312 \mathrm{~nm}$. As shown in Figure 2, the fluorescence intensity of the ligand NA-LCX gradually decreased upon the addition of $\mathrm{Cu}^{2+}$ ions and became constant until about 2 equiv. of $\mathrm{Cu}^{2+}$ ions were added. The quenching rate was extremely high, indicating that probe NA-LCX was highly sensitive to $\mathrm{Cu}^{2+}$, which could be due to the photoinduced electron transfer of $\mathrm{Cu}^{2+}$ ions and/or the d-d electron paramagnetic quenching effect [41-43]. Moreover, the fluorescence emission intensity showed a good linear relationship

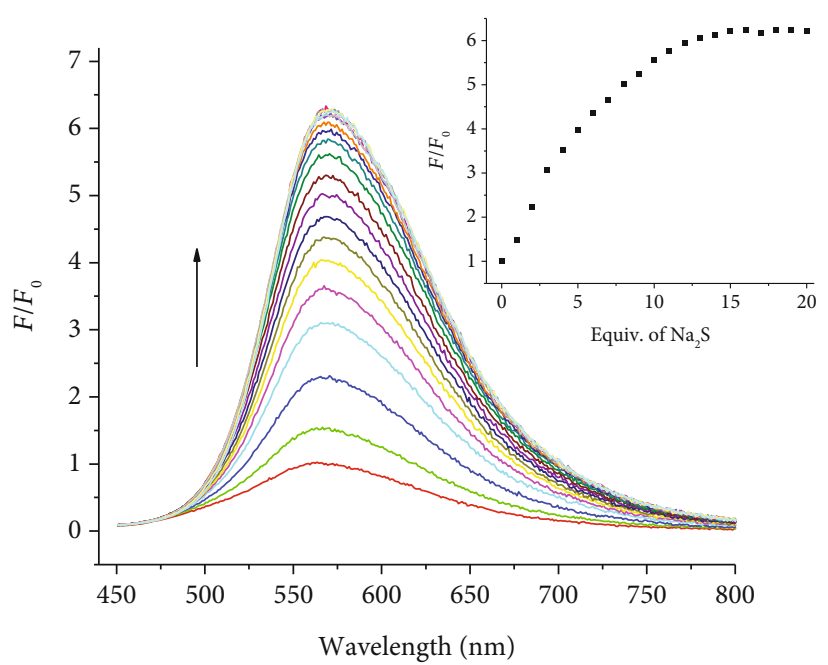

FIgURE 3: Fluorescence spectra change of probe NA-LCX-Cu ${ }^{2+}$ $(20 \mu \mathrm{M})$ with the titration of $\mathrm{Na}_{2} \mathrm{~S}$ in DMSO:HEPES $(3: 2, v / v)$ solution at an excitation of $312 \mathrm{~nm}$. Inset figure: $F / F_{0}$ intensity for NA-LCX-Cu ${ }^{2+}$ at $575 \mathrm{~nm}$ vs. different equivalents of $\mathrm{Na}_{2} \mathrm{~S}$.

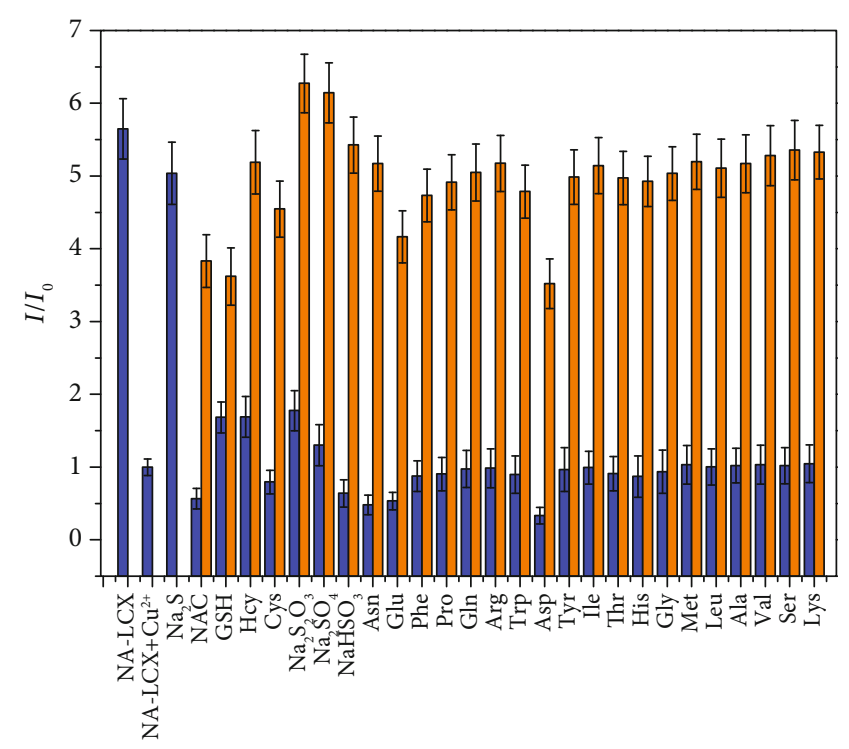

FIGURE 4: Blue: fluorescence response of probe NA-LCX-Cu ${ }^{2+}$ $(20 \mu \mathrm{M})$ toward 10 equiv. of various amino acids (NA-LCX $+\mathrm{Cu}^{2+}$, $\mathrm{Na}_{2} \mathrm{~S}, \mathrm{NAC}, \mathrm{GSH}, \mathrm{Hcy}, \mathrm{Cys}$, Asn, Glu, Phe, Pro, Gln, Arg, Trp, Asp, Tyr, Ile, Thr, His, Gly, Met, Leu, Ala, Val, Ser, and Lys) and other reactive sulfur species $\left(\mathrm{Na}_{2} \mathrm{~S}_{2} \mathrm{O}_{3}, \mathrm{Na}_{2} \mathrm{SO}_{4}\right.$, and $\left.\mathrm{NaHSO}_{3}\right)$. Orange: fluorescence response of probe NA-LCX-Cu ${ }^{2+}$ after addition of 10 equiv. of $\mathrm{Na}_{2} \mathrm{~S}$ in each of the above solutions.

$\left(R^{2}=0.99\right)$ with the concentration of $\mathrm{Cu}^{2+}$ ions in the range of $1 \sim 20 \mu \mathrm{M}$. The quenching constant value of probe NALCX with $\mathrm{Cu}^{2+}$ ions was determined from the titration plots. The corrected Stern-Volmer fitting indicated the value of $2.6 \times 10^{4} \mathrm{~mol}^{-1} \cdot \mathrm{L}$ (Figure S5). The fluorescence response of probe NA-LCX to other metal ions in DMSO:HEPES $(3: 2$, $v / v)$ was shown in Figure S6. It could be found that many other metal ions, such as $\mathrm{Co}^{2+}, \mathrm{Fe}^{3+}$. It could be found that many other metal ions, such as $\mathrm{Co}^{2+}, \mathrm{Fe}^{3+}, \mathrm{Fe}^{2+}, \mathrm{Ni}^{2+}, \mathrm{Zn}^{2+}$, 

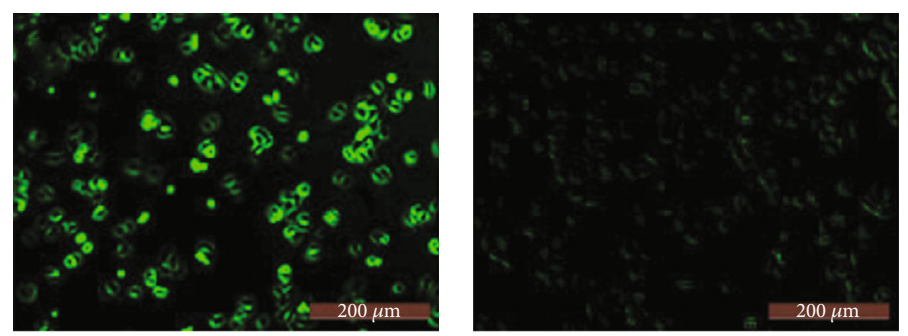

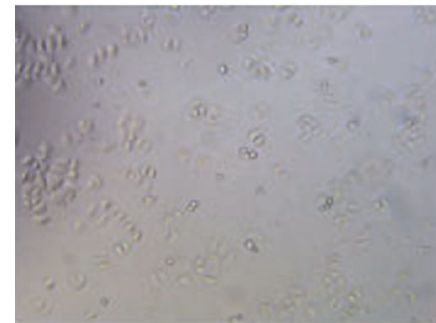

(a)
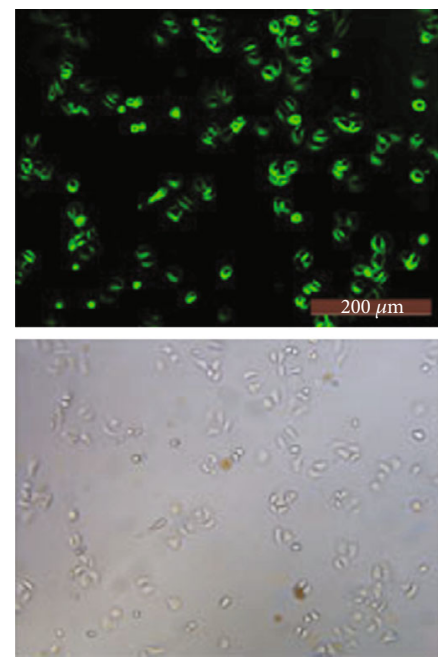

(c)

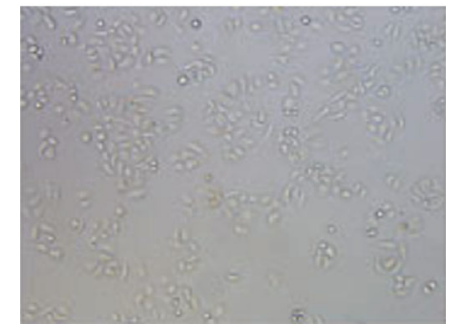

(b)
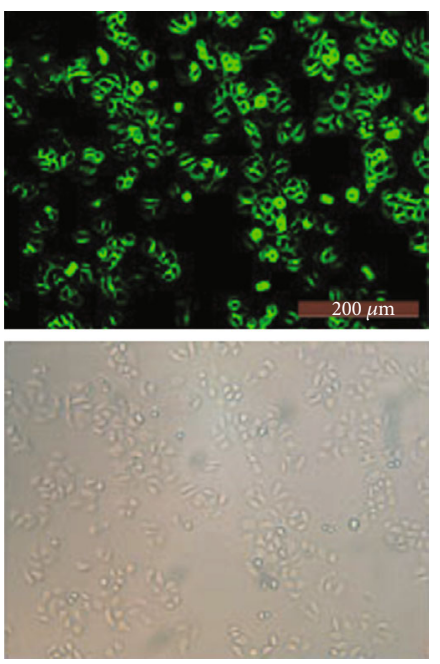

(d)

FIGURE 5: The fluorescence images of HepG-2 cells with the incubation of (a) ligand NA-LCX ( $3 \mu \mathrm{M}),(\mathrm{b})$ complex NA-LCX-Cu${ }^{2+}(3 \mu \mathrm{M})$, (c) complex NA-LCX-Cu ${ }^{2+}$ with the addition of 2 equiv. $\mathrm{Na}_{2} \mathrm{~S}$, and (d) complex NA-LCX-Cu ${ }^{2+}$ with the addition of 5 equiv. $\mathrm{Na}_{2} \mathrm{~S}$ and their corresponding bright field images.

$\mathrm{Cd}^{2+}$, and $\mathrm{Mn}^{2+}$, also exhibited a similar fluorescence quenching response.

3.3. Fluorescence Spectra Response of Complex NA-LCX-Cu ${ }^{2+}$ toward $\mathrm{H}_{2} \mathrm{~S}$. The complex formed by probe NA-LCX and $\mathrm{Cu}^{2+}$ was used as a new sensor NA-LCX-Cu ${ }^{2+}$ for sequential recognition of $\mathrm{H}_{2} \mathrm{~S}$. Upon the addition of $\mathrm{Na}_{2} \mathrm{~S}$, as shown in Figure 3, the fluorescence intensity was gradually increased and remained unchanged up to 10 equiv. The probe NA-LC-Cu${ }^{2+}$ released $\mathrm{Cu}^{2+}$ ions due to the strong reaction between sulfide and copper ions, which restored the original fluorescence of the probe. Furthermore, the detection limit was $2.79 \mu \mathrm{M}$ according to the formula $\mathrm{LOD}=3 \sigma / S$ (Figure S7). The responses of ligand NALCX to other metal ions such as $\mathrm{Co}^{2+}, \mathrm{Cd}^{2+}, \mathrm{Zn}^{2+}, \mathrm{Ni}^{2+}$, $\mathrm{Fe}^{2+}, \mathrm{Mn}^{2+}$, and $\mathrm{Fe}^{3+}$ and the subsequent addition of 10 equiv. of $\mathrm{Na}_{2} \mathrm{~S}$ are shown in Figure S8. It could be found that the complex NA-LCX-Cu ${ }^{2+}$ possess the highest fluorescence intensity ratio of recovery/quenching, and hence, the probe NA-LCX-Cu ${ }^{2+}$ was chosen to pursue $\mathrm{H}_{2} \mathrm{~S}$ detection.

To further explore whether probe NA-LCX-Cu ${ }^{2+}$ could be used as a highly selective $\mathrm{H}_{2} \mathrm{~S}$ sensor, the fluorescence response of probe NA-LCX-Cu ${ }^{2+}(20 \mu \mathrm{M})$ to different amino acids was tested. As described and shown in Figure 4, only the addition of $\mathrm{H}_{2} \mathrm{~S}$ instantly caused an obvious fluorescence enhancement. The fluorescence intensity of probe NA-LCX$\mathrm{Cu}^{2+}$ remains unchanged in the presence of 10 equiv. of different mercapto-amino acids such as glutathione, cysteine, $\mathrm{N}$-acetyl-L-cysteine, homocysteine, and non-mercaptoamino acids. And other reactive sulfur species $\left(\mathrm{S}_{2} \mathrm{O}_{3}{ }^{2-}\right.$, $\mathrm{SO}_{4}{ }^{2-}$, and $\mathrm{HSO}_{3}{ }^{-}$) also did not cause obvious fluorescence changes. The competitive experiments further showed significant fluorescent enhancement without being interfered by 
other amino acids and reactive sulfur species, which further indicated the good selectivity of the probe NA-LCX-Cu ${ }^{2+}$ for $\mathrm{H}_{2} \mathrm{~S}$ detection.

3.4. DFT Calculation. To gain further insight into the nature of coordination configuration and optical response of sensor NA-LCX toward $\mathrm{Cu}^{2+}$, the different coordination structures of NA-LCX-Cu ${ }^{2+}$ were examined by density functional theory calculation. All calculations were performed by Gaussian 09 program. The geometries were optimized at the B3LYP/6-31G(d)/SDD level, and the interaction energies were calculated based on the single point energies obtained at the B3LYP/6-31+G(d)/SDD level. As shown in Figure S9, it was obvious that the interaction energy of structure $\mathrm{C}$ was higher than structures $\mathrm{A}$ and $\mathrm{B}$, which verified the experimental results and presumed the complexation mode of probe NA-LCX with $\mathrm{Cu}^{2+}$.

3.5. Effect of $p H$ on the Performance of Probe NA-LCX and Complex $\mathrm{NA}-\mathrm{LCX}-\mathrm{Cu}^{2+}$. To investigate the effect of $\mathrm{pH}$ value, fluorescence intensity of probe NA-LCX, complex NA-LCX$\mathrm{Cu}^{2+}$, and complex NA-LCX-Cu ${ }^{2+}$ in the presence of $\mathrm{S}^{2-}$ was investigated in a wide range of $\mathrm{pH}$ values. No significant changes in fluorescence intensity were found at lower $\mathrm{pH}$ $(\mathrm{pH} \leq 6)$ (Figure $\mathrm{S} 10)$. However, It could be observed that significant fluorescence changes in ligand NA-LCX and NA-LCX- $-\mathrm{Cu}^{2+}-\mathrm{Na}_{2} \mathrm{~S}$ at $\mathrm{pH}>6$, indicating potential of probe NA-LCX-Cu ${ }^{2+}$ to detect $\mathrm{H}_{2} \mathrm{~S}$ in physiological environments.

3.6. Cell Imaging Experiments. Inspired by the excellent selectivity at physiological $\mathrm{pH}$ levels, the cell imaging application of sensor NA-LCX for detection of $\mathrm{Cu}^{2+}$ and $\mathrm{H}_{2} \mathrm{~S}$ was further investigated. Prior to the cell imaging experiment, the MTT cell toxicity assay for probe NA-LCX-Cu ${ }^{2+}$ was performed in human liver cancer cells (HepG-2) shown in Figure S11, and no significant cytotoxicity was found in the range of $0 \sim 10 \mu \mathrm{M}$, even after incubating for $24 \mathrm{~h}$. As shown in Figure 5, significant intracellular green fluorescence in the HepG-2 cells was observed in the presence of probe NALCX when excited with blue light (Figure 5(a)), indicating that the sensor NA-LCX was well permeable. However, the complex NA-LCX-Cu ${ }^{2+}$ was added to the wells, and the green fluorescence in HepG-2 cells was quenched to a large degree, as expected (Figure 5(b)). Upon subsequent addition of 2 and 5 equiv. of $\mathrm{Na}_{2} \mathrm{~S}$ solution, obvious fluorescence recovery was observed (Figures 5(c) and 5(d)). The fluorescence imaging results suggested the potential of probe NA-LCX-Cu ${ }^{2+}$ for in vivo detection of $\mathrm{H}_{2} \mathrm{~S}$.

\section{Conclusion}

In this study, a novel two-armed naphthalene derivative probe NA-LCX was synthesized and its spectral performance for sequential recognition of $\mathrm{Cu}^{2+}$ and $\mathrm{H}_{2} \mathrm{~S}$ was studied. The probe NA-LCX showed an obvious "on-off-on" fluorescence response toward $\mathrm{Cu}^{2+}$ and $\mathrm{H}_{2} \mathrm{~S}$. The probe NA-LCX showed a 1:1 binding stoichiometry to $\mathrm{Cu}^{2+}$ with a complexation constant of $2.6 \times 10^{4} \mathrm{M}^{-1}$. Fluorescence study indicated sen- sitivity and selectivity of the probe NA-LCX-Cu ${ }^{2+}$ for $\mathrm{H}_{2} \mathrm{~S}$ detection without interference from other amino acids. The detection limit for $\mathrm{H}_{2} \mathrm{~S}$ was calculated to be $2.79 \mu \mathrm{M}$. The cell imaging results further showed the potential of the probe for $\mathrm{Cu}^{2+}$ and $\mathrm{H}_{2} \mathrm{~S}$ detection in living cells.

\section{Data Availability}

The data used to support the findings of this study are included within the article and supplementary information file(s).

\section{Conflicts of Interest}

Authors declare that there is no conflict of interest regarding the publication of this paper.

\section{Authors' Contributions}

Guanglan Mao and Chenxi Liu contributed equally to this work.

\section{Acknowledgments}

We gratefully acknowledge the financial support from the Natural Science Foundation of Henan Province (No. 182300410309), Key Scientific and Technological Project of Henan Province (No. 182102310648), and Key Scientific Research Project of Higher Education Institutions of Henan Province (No. 18A150044).

\section{Supplementary Materials}

Supplementary data associated with this article can be found in the online version. The synthesis characterization of probe NA-LCX and specific test conditions for spectra reported in this article have been deposited in the supplementary material. Figures S1, S2, and S3: the NMR and MS spectra of probe NA-LCX. Figure S4: Job's plot fitting of probe NA-LCX with $\mathrm{Cu}^{2+}$. Figure S5: the Stern-Volmer fitting of probe NA-LCX with $\mathrm{Cu}^{2+}$. Figure S6: fluorescence spectra of probe NALCX upon addition of various metal ions. Figure S7: the fluorescence intensity of probe NA-LCX-Cu ${ }^{2+}$ with addition of $\mathrm{H}_{2} \mathrm{~S}$. Figure S8: the fluorescence responses of probe NALCX in the presence of various metal ions and subsequent addition of $\mathrm{H}_{2} \mathrm{~S}$. Figure S9: the density functional theory (DFT) calculation of different coordination structure of NA-LCX-Cu ${ }^{2+}$. Figure S10: the fluorescence intensity of probe NA-LCX, probe NA-LCX-Cu ${ }^{2+}$, and probe NA-LCX$\mathrm{Cu}^{2+}$ upon addition of $\mathrm{Na}_{2} \mathrm{~S}$ at different $\mathrm{pH}$ values. Figure S11: the MTT experiment of probe NA-LCX-Cu ${ }^{2+}$. Scheme S1: the Cartesian coordinate data of complex NA-LCX$\mathrm{Cu}^{2+}$. (Supplementary Materials)

\section{References}

[1] Y. K. Gupta, A. K. Dahiya, and K. H. Reeta, "Gaso-transmitter hydrogen sulphide: potential new target in pharmacotherapy," Indian Journal of Experimental Biology, vol. 48, p. 1069, 2010. 
[2] E. Lowicka and J. Beltowski, "Hydrogen sulfide $\left(\mathrm{H}_{2} \mathrm{~S}\right)$-the third gas of interest for pharmacologists," Pharmacological Reports, vol. 59, p. 4, 2007.

[3] A. di Masi and P. Ascenzi, " $\mathrm{H}_{2} \mathrm{~S}$ : a "double face" molecule in health and disease," BioFactors, vol. 39, no. 2, pp. 186-196, 2013.

[4] N. L. Kanagy, C. Szabo, and A. Papapetropoulos, "Vascular biology of hydrogen sulfide," American Journal of PhysiologyCell Physiology, vol. 312, no. 5, pp. C537-C549, 2017.

[5] N. Sen, "Functional and molecular insights of hydrogen sulfide signaling and protein sulfhydration," Journal of Molecular Biology, vol. 429, no. 4, pp. 543-561, 2017.

[6] R. Yang, Y. Liu, and S. Shi, "Hydrogen sulfide regulates homeostasis of mesenchymal stem cells and regulatory $\mathrm{T}$ cells," Journal of Dental Research, vol. 95, no. 13, pp. 14451451, 2016.

[7] J. Bełtowski, G. Wójcicka, and A. Jamroz-Wiśniewska, "Hydrogen sulfide in the regulation of insulin secretion and insulin sensitivity: Implications for the pathogenesis and treatment of diabetes mellitus," Biochemical Pharmacology, vol. 149, pp. 60-76, 2018.

[8] L. L. Pan, M. Qin, X. H. Liu, and Y. Z. Zhu, "The role of hydrogen sulfide on cardiovascular homeostasis: an overview with update on immunomodulation," Frontiers in Pharmacology, vol. 8 , p. 686, 2017.

[9] Z. J. Wang, J. Wu, W. Guo, and Y. Z. Zhu, "Atherosclerosis and the hydrogen sulfide signaling pathway - therapeutic approaches to disease prevention," Cellular Physiology and Biochemistry, vol. 42, no. 3, pp. 859-875, 2017.

[10] Y. H. Chen, W. Z. Yao, B. Geng et al., "Endogenous hydrogen sulfide in patients with COPD," Chest, vol. 128, no. 5, pp. 3205-3211, 2005.

[11] N. Bazhanov, M. Ansar, T. Ivanciuc, R. P. Garofalo, and A. Casola, "Hydrogen sulfide: a novel player in airway development, pathophysiology of respiratory diseases, and antiviral defenses," American Journal of Respiratory Cell and Molecular Biology, vol. 57, no. 4, pp. 403-410, 2017.

[12] H. Zhang, H. Zhang, L. Li et al., "TIPS versus endoscopic therapy for variceal rebleeding in cirrhosis: A meta-analysis update," Journal of Huazhong University of Science and Technology [Medical Sciences], vol. 37, no. 4, pp. 475-485, 2017.

[13] W. W. Wei, C. Wang, and D. J. Li, "The content of hydrogen sulfide in plasma of cirrhosis rats combined with portal hypertension and the correlation with indexes of liver function and liver fibrosis," Experimental and Therapeutic Medicine, vol. 14, no. 5, pp. 5022-5026, 2017.

[14] K. Eto, T. Asada, K. Arima, T. Makifuchi, and H. Kimura, "Brain hydrogen sulfide is severely decreased in Alzheimer's disease," Biochemical and Biophysical Research Communications, vol. 293, no. 5, pp. 1485-1488, 2002.

[15] Y. Y. Liu and J. S. Bian, "Hydrogen sulfide protects amyloid- $\beta$ induced cell toxicity in microglia," Journal of Alzheimer's Disease, vol. 22, no. 4, pp. 1189-1200, 2010.

[16] X. Zhang, W. Zhou, Z. Yuan, and C. Lu, "Colorimetric detection of biological hydrogen sulfide using fluorosurfactant functionalized gold nanorods," Analyst, vol. 140, no. 21, pp. 74437450, 2015.

[17] Z. Gao, D. Tang, D. Tang, R. Niessner, and D. Knopp, “Targetinduced nanocatalyst deactivation facilitated by core@shell nanostructures for signal-amplified headspace-colorimetric assay of dissolved hydrogen sulfide," Analytical Chemistry, vol. 87, no. 19, pp. 10153-10160, 2015.

[18] M. Liu, L. Zhang, Y. Hua et al., "Mesoporous silver-melamine nanowires formed by controlled supermolecular self-assembly: a selective solid-state electroanalysis for probing multiple sulfides in hyperhaline media through the specific sulfide-chloride replacement reactions," Analytical Chemistry, vol. 89, no. 17, pp. 9552-9558, 2017.

[19] X. Yue, Z. Zhu, M. Zhang, and Z. Ye, "Reaction-based turn-on electrochemiluminescent sensor with a ruthenium(II) complex for selective detection of extracellular hydrogen sulfide in rat brain," Analytical Chemistry, vol. 87, no. 3, pp. 1839$1845,2015$.

[20] S. Koike, K. Kawamura, Y. Kimura, N. Shibuya, H. Kimura, and Y. Ogasawara, "Analysis of endogenous $\mathrm{H}_{2} \mathrm{~S}$ and $\mathrm{H}_{2} \mathrm{Sn}$ in mouse brain by high-performance liquid chromatography with fluorescence and tandem mass spectrometric detection," Free Radical Biology \& Medicine, vol. 113, pp. 355-362, 2017.

[21] S. Arndt, C. D. Baeza-Garza, A. Logan et al., "Measuring $\mathrm{H}_{2} \mathrm{~S}$ with MitoA," The Journal of Biological Chemistry, vol. 292, no. 19, pp. 7761-7773, 2017.

[22] S. K. Asthana, A. Kumar, N. Neeraj, S. Shweta, and K. K. Upadhyay, "Efficient visualization of $\mathrm{H}_{2} \mathrm{~S}$ via a fluorescent probe with three electrophilic centres," Organic \& Biomolecular Chemistry, vol. 14, no. 15, pp. 3690-3694, 2016.

[23] P. K. Mishra, T. Saha, and P. Talukdar, "Hydrogen sulfide mediated cascade reaction forming an iminocoumarin: applications in fluorescent probe development and live-cell imaging," Organic \& Biomolecular Chemistry, vol. 13, no. 27, pp. 7430-7436, 2015.

[24] Y. Zhang, H. Chen, D. Chen, X. C. Di Wu, S. H. Liu, and J. Yin, "A fluorescent turn-on $\mathrm{H}_{2} \mathrm{~S}$-responsive probe: design, synthesis and application," Organic \& Biomolecular Chemistry, vol. 13, no. 38, pp. 9760-9766, 2015.

[25] Z. Guo, G. Chen, G. Zeng et al., "Fluorescence chemosensors for hydrogen sulfide detection in biological systems," Analyst, vol. 140, no. 6, pp. 1772-1786, 2015.

[26] X. L. Liu, X. J. Du, C. G. Dai, and Q. H. Song, "Ratiometric two-photon fluorescent probes for mitochondrial hydrogen sulfide in living cells," The Journal of Organic Chemistry, vol. 79, no. 20, pp. 9481-9489, 2014.

[27] Y. Jiang, Q. Wu, and X. J. Chang, "A ratiometric fluorescent probe for hydrogen sulfide imaging in living cells," Talanta, vol. 121, pp. 122-126, 2014.

[28] X. Wang, J. Sun, W. Zhang, X. Ma, J. Lv, and B. Tang, “A nearinfrared ratiometric fluorescent probe for rapid and highly sensitive imaging of endogenous hydrogen sulfide in living cells," Chemical Science, vol. 4, no. 6, p. 2551, 2013.

[29] C. R. Liu, B. Peng, S. Li, C. M. Park, A. R. Whorton, and M. Xian, "Reaction based fluorescent probes for hydrogen sulfide," Organic Letters, vol. 14, no. 8, pp. 2184-2187, 2012.

[30] X. Y. Cao, W. Lin, K. Zheng, and L. He, “A near-infrared fluorescent turn-on probe for fluorescence imaging of hydrogen sulfide in living cells based on thiolysis of dinitrophenyl ether," Chemical Communications, vol. 48, no. 85, pp. 10529-10531, 2012.

[31] Z. T. Zhu, W. Liu, L. H. Cheng, Z. F. Li, Z. Xi, and L. Yi, "New NBD-based fluorescent probes for biological thiols," Tetrahedron Letters, vol. 56, no. 25, pp. 3909-3912, 2015.

[32] J. J. Wang, L. P. Long, D. Xie, and Y. W. Zhan, "Highly selective fluorescence turn-on sensor for hydrogen sulfide and 
imaging in living cells," Journal of Luminescence, vol. 139, pp. 40-46, 2013.

[33] J. Liu, X. D. Guo, R. Hu et al., "Molecular engineering of aqueous soluble triarylboron-compound-based two-photon fluorescent probe for mitochondria $\mathrm{H}_{2} \mathrm{~S}$ with analyte-induced finite aggregation and excellent membrane permeability," Analytical Chemistry, vol. 88, no. 1, pp. 1052-1057, 2015.

[34] Y. Chang, H. Qin, X. Wang et al., "Visible and reversible restrict of molecular configuration by copper ion and pyrophosphate," ACS Sensors, vol. 5, no. 8, pp. 2438-2447, 2020.

[35] R. Kaushik, R. Sakla, A. Ghosh, G. T. Selvan, P. M. Selvakumar, and D. A. Jose, "Selective detection of $\mathrm{H}_{2} \mathrm{~S}$ by copper complex embedded in vesicles through metal indicator displacement approach," ACS Sensors, vol. 3, no. 6, pp. 1142-1148, 2018.

[36] Y. Chang, J. Fu, K. Yao, B. Li, K. Xu, and X. Pang, "Novel fluorescent probes for sequential detection of $\mathrm{Cu}^{2+}$ and citrate anion and application in living cell imaging," Dyes and Pigments, vol. 161, pp. 331-340, 2019.

[37] Z. Tang, B. Song, H. Ma, Y. Shi, and J. Yuan, “A ratiometric time-gated luminescence probe for hydrogen sulfide based on copper(II)-coupled lanthanide complexes," Analytica Chimica Acta, vol. 1049, pp. 152-160, 2019.

[38] P. Wang, K. Yao, J. Fu, Y. Chang, B. Li, and K. Xu, "Novel fluorescent probes for relay detection copper/citrate ion and application in cell imaging," Spectrochimica Acta. Part A, Molecular and Biomolecular Spectroscopy, vol. 211, pp. 9-17, 2019.

[39] H. Wang, D.-L. Shi, J. Li, H.-Y. Tang, J. Li, and Y. Guo, “A facile fluorescent probe with a large Stokes shift for sequentially detecting copper and sulfide in $100 \%$ aqueous solution and imaging them in living cells," Sensors and Actuators B: Chemical, vol. 256, pp. 600-608, 2018.

[40] P. Wang, J. Fu, K. Yao, Y. Chang, K. Xu, and Y. Xu, "A novel quinoline-derived fluorescent "turn-on" probe for $\mathrm{Cu}^{2+}$ with highly selectivity and sensitivity and its application in cell imaging," Sensors and Actuators B: Chemical, vol. 273, pp. 1070-1076, 2018.

[41] G. J. He, C. X. Liu, X. B. Liu et al., "Design and synthesis of a fluorescent probe based on naphthalene anhydride and its detection of copper ions," PLoS One, vol. 12, no. 10, p. e0186994, 2017.

[42] G. J. He, C. X. Liu, J. H. Xu et al., "Synthesis and application of a highly selective copper ions fluorescent probe based on the coumarin group," Spectrochimica Acta. Part A, Molecular and Biomolecular Spectroscopy, vol. 190, pp. 116-120, 2018.

[43] G. J. He, J. Li, Z. Q. Wang et al., "Synthesis of a fluorogenic probe for thiols based on a coumarin schiff base copper complex and its use for the detection of glutathione," Tetrahedron, vol. 73, no. 3, pp. 272-277, 2017. 